\title{
Microneurosurgical Management of Upper Cervical Spinal Schwannoma: An Experience of 30 Cases
}

\author{
Rahman $\mathrm{MA}^{1}$, Mitra $\mathrm{PK}^{2}$, Habib $\mathrm{R}^{3}$, Islam $\mathrm{KMT}^{4}$, Amin $\mathrm{MR}^{5}$, Mahmood $\mathrm{E}^{6}$
}

Conflict of interest: There is no conflict of interest relevant to this paper to disclose.

Funding Agency: Was not funded by any institute or any group.

Contribution of Authors: Rahman MA was Principal investigator, Mitra PK help for protocol preparation, Habib R, Islam KMT, Amin MR help for data collection and Mahmood E help for editorial formatting.

Copyright: @2019 Bang. JNS published by BSNS. This article is published under the creative commons CC-BY-NC license.

This license permits use distribution (https://creativecommons.orgf/ licences/by-nc/4-0/) reproduction in any medium, provided the original work is properly cited, and is not used for commercial purposes.

Received: 25 February, 2019

Accepted: 16 March, 2019

\begin{abstract}
:
Aim: We prospectively recorded the clinical features, radiological features, surgical approaches \& findings, postoperative follow up \& ultimate neurological outcome of upper cervical spinal schwannomas and then we evaluated the records retrospectively.

Materials and Method: 30 upper cervical spinal schwannomas patient who underwent surgery (microneurosurgically) from 2007 to 2014 in the department of neurosurgery Dhaka Medical College and private hospitals are included in this retrospective study. After operation all patients were followed up regularly both clinically and neuro-radiologically.
\end{abstract}

Results: Out of 30 cases 16 male and 14 females. The male to female ratio was 1.4: 1, Age range from 8 to 60 years with mean age 35 Years. Most of the patients are in middle years age group The mean duration of symptoms at the time of presentation was 32 months (range 06 months-5 years). Four schwannomas were completely extradural, fourteen were intradural and rest twelve were intradural or hourglass type (both extra and intradural) as identified during surgery. The posterior midline approach was used in all patients. A C2 hemilaminectomy or C2 laminectomy with or without cutting of posterior arch of atlas was used for most intradural and large in terdural C2 schwannomas. Tumor removal was complete in all cases. Preservation of the nerve root fibers was not possible in 18 cases and was possible only in 12 cases. In one patients CSF leak developed after operation. One patient who had severe myelopathic features with bed sore failed to improve and expired 5 months after operation. Rest of the patients showed postoperative improvement in their preoperative symptoms and returned to their normal life by the end of sixth month. There was one tumor recurrence in any patient till last follow up.

Conclusion: Proper 3-D anatomical orientation \& physiological knowledge, deep neuro-radiological observation, pathological appreciations and micro-neurosurgical skill and expertization can make the surgical management of these tumors ( in a surgically complex site) simple with gratifying result (i.e.neurological outcome) without extensive bone removal or soft tissue manipulation through a standard midline posterior approach.

Key Words: High cervical schwannoma; Spinal schwannoma; Micro-neurosurgical management.

Bang. J Neurosurgery 2019; 9(1): 44-48

\section{Introduction:}

Spinal schwannoma and meningioma constitutes the main bulk of spinal extramedullary tumor ${ }^{1}$. Schwannoma arising from upper cervical spinal roots are commoner than any other spinal nerves ${ }^{1-3}$. This type of schwannoma may be intradural, extradural or hourglass form (intra and extradural). In this article, we prospectively recorded the clinical features,

1. Dr. Md Atikur Rahman, Associate Professor, Neurosurgery Dept., Bangbandhu Sheikh Mijub Medical University, Dhaka-1000

2. Dr. Pijush Kanti Mitra, Assistant Professor, Neurosurgery Dept., Dhaka Medical College Hospital

3. Dr. Riad Habib, Resident, Neurosurgery Dept., Bangbandhu Sheikh Mijub Medical University, Dhaka-1000

4. Dr. Md. KM Tariqul Islam, Associate Professor, Neurosurgery Dept., Bangbandhu Sheikh Mijub Medical University, Dhaka-1000

5. Dr. Md. Rezaul Amin, Associate Professor, Neurosurgery Dept., Bangbandhu Sheikh Mijub Medical University, Dhaka-1000

6. Professor Ehsan Mahmood, Ex Professor and Head, Neurosurgery Dept., Dhaka Medical College Hospital

Address of Correspondence: Dr. Md Atikur Rahman, Associate Professor, Neurosurgery Dept., Bangbandhu Sheikh Mijub Medical University, Dhaka-1000. Email. atiquessmc@yahoo.com, mobile: 01715011169. 
radiological features, surgical approaches \& findings, postoperative follow up \& ultimate neurological outcome of high cervical spinal schwannomas and then we evaluated the records retrospectively.

\section{Materials and Method:}

All patients who were diagnosed as a case of high cervical spinal schwannoma on the basis of MRI findings and confirmed by preoperative finding and postoperative histopathology were included in this series. In this series, schwannomas arising from C1, C2 and C3 spinal nerve roots were regarded as 'high cervical spinal schwannoma' (Fig-1). All patients were consecutively operated microneurosurgically in the department of Neurosurgery, Dhaka Medical College Hospital, and private hospitals from 2007 to 2014. Preoperatively all clinical features and radiological findings were recorded for comparison with that of post-operative follow up. Operative procedures and per operative findings were noted properly (Fig:-2). Histopathological report and early post-operative complication (if any) were also recorded carefully. Postoperatively all patients were followed up regularly both clinically and neuroradiologically (MRI of cervical spine). Clinical features, radiological features, surgical approaches \& peroperative findings, postoperative follow up and ultimate neurological outcomes were studied.

\section{Results:}

Studied include 16 male and 14 female. (Fig:-2) The male to female ratio was 1.4: 1 , Age range from 8 to 60 years with mean age 35 Years. Most of the patients are in middle years age group The mean duration of symptoms at the time of presentation was 32 months (range 06 months-5 years). In this series, schwannomas arising from $\mathrm{C} 1, \mathrm{C} 2$ and $\mathrm{C} 3$ spinal nerve roots were regarded as 'high cervical spinal schwannoma'. All patients who were diagnosed as a case of high cervical spinal schwannoma on the basis of MRI findings and confirmed by preoperative finding and postoperative histopathology were included in this series. All patients are included in this retrospective study. were consecutively operated microneurosurgically from 2007 to 2014 in the department of neurosurgery Dhaka Medical College and private hospitals. Preoperatively all clinical features and radiological findings were recorded for comparison with that of post-operative follow up. Operative procedures and per operative findings were noted properly.
Histopathological report and early post-operative complication (if any) were also recorded carefully. Postoperatively all patients were followed up regularly both clinically and neuroradiologically (MRI of cervical spine). Clinical features, radiological features, surgical approaches \& peroperative findings, postoperative follow up and ultimate neurological outcomes were studied. The incision extended from the occipital protuberance down to the $\mathrm{C} 4$ spinous process. The C2 spinous process was widely exposed on the side of the tumor and the paraspinal muscles were dissected subperiosteally to expose the C2 lamina \& the pedicle and the lateral aspect of the arch of the atlas. For tumor originating from C3, C3 lamina was also exposed. In extradural and small hourglass (interdural) tumor originating $\mathrm{C} 2$ were excised completely without any bony resection through intratumoral resection technique. In most cases, a C2 hemilaminectomy or C2 laminectomy with or without cutting of posterior arch of atlas was used for most intradural and large intraextradural C2 schwannomas. One of the $\mathrm{C} 3$ extradural schwannoma was removed by exposing the canal through lateral mass (Figure 3), facet joint on that side was compromised where fusion done after tumor removal. In rest of the cases joint instability was not suspected after tumor removal. Other case of C3 schwannoma was removed by removing C2 and C3 lamina. In C1 nerve root schwannoma, posterior arch of atlas excision (more on the tumor side) with small suboccipital craniectomy was used for tumor removal. Among the 30 cases, 6 were $\mathrm{C} 1$ (Figure 1 ), 7 were C 3 and rest 17 was $C 2$ schwannoma. In no case VAcame in view and no volunteer effort was made to see the VA. In C2 schwannoma venous sinus seemed to be pushed back and compressed. It did not make any troublesome venous bleeding in any case. When the posterior surface of the tumor was exposed, its posterior dural wall was incised and intra tumoral debulking was performed. Most of the tumors were firm in nature; some were soft and friable. Bleeding was minimum in most of the cases. No cyst or cystic degeneration was found in any of the cases. Preservation of the nerve root fibers was not possible in 18 cases. In 6 cases nerve roots were partially preserved and total nerve root preservation was possible only in 6 cases. Tumor removal was complete in all cases. One patients developed CSF leak through the wound post operatively. Histopathological examination confirmed schwannoma. One patient who 

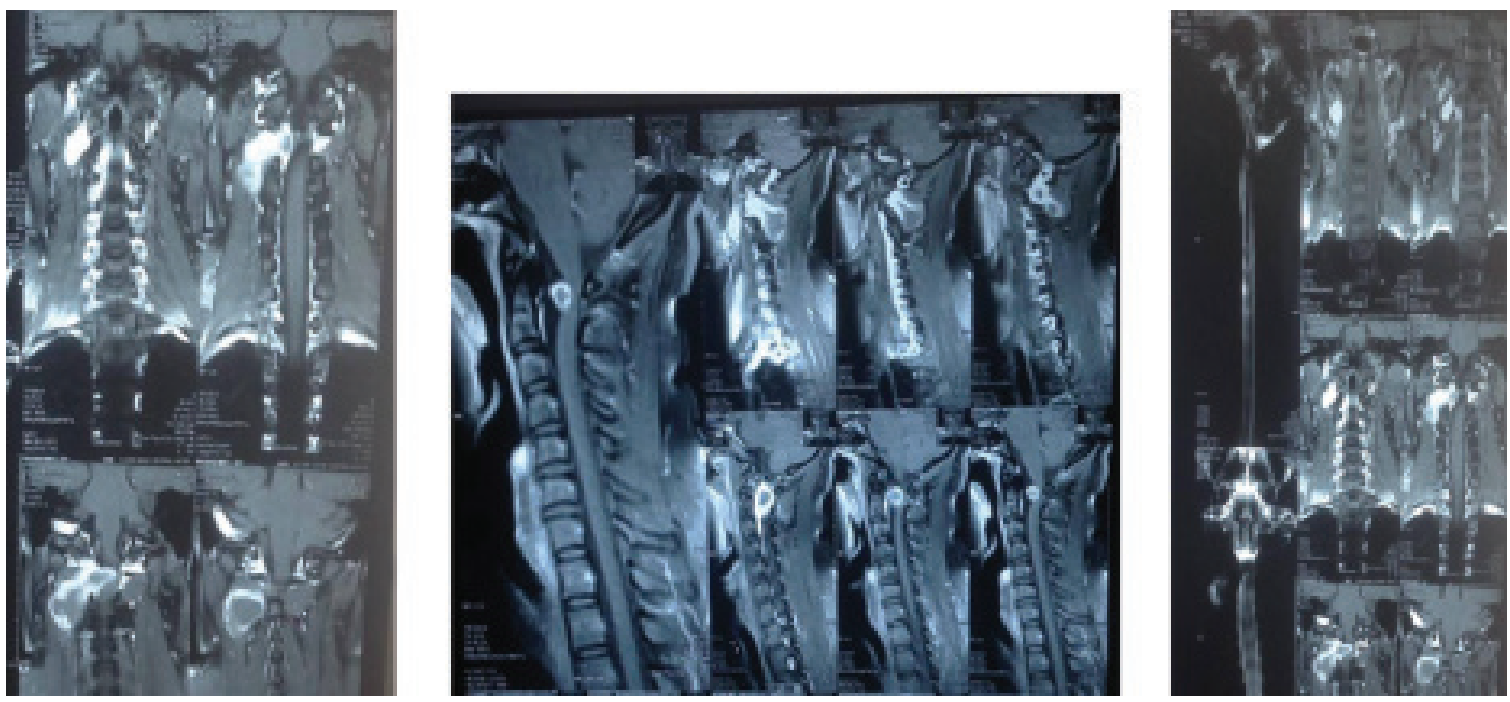

Fig-1: MRI of Cervical Spine Shows C1/C2 intradural extramedullary with extradural Schwannoma

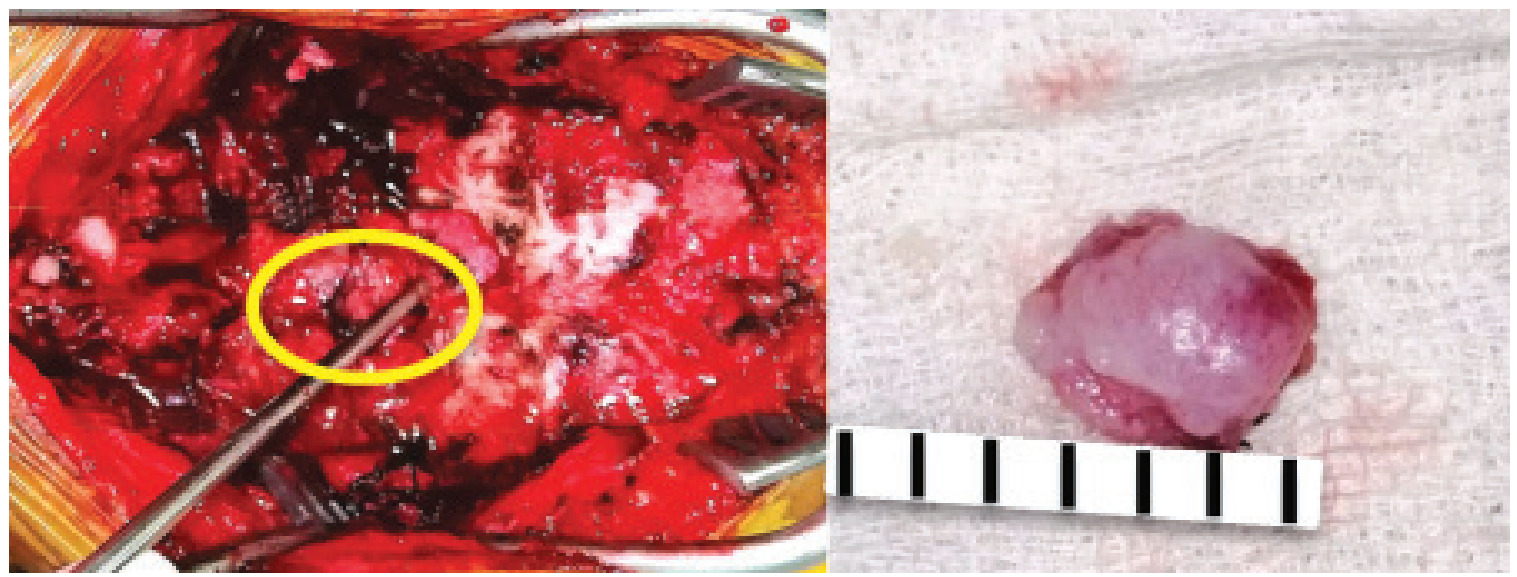

Fig-2: Per operative and tumor After removal

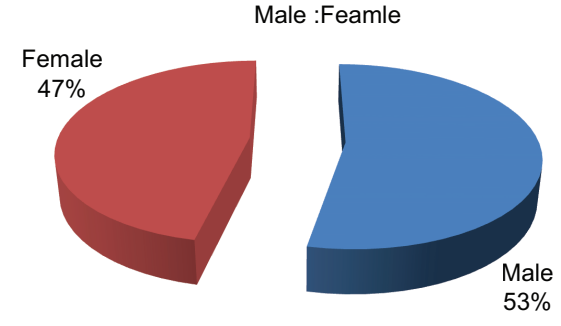

Fig.-3: Shows Male: Female

had severe myelopathic features with bed sores failed to improve and expired 5 months after operation from bed sore, urinary tract infection and hypostatic pneumonia. One case, patient improved neurologically and returned to his daily life with mild motor deficit (MRC grade 4+/5) and mild spasticity that persisted at last follow up (12 months after operation). Rest of the patients showed postoperative improvement in their preoperative symptoms and returned to their normal life by the end of six months. No patient complained for dysesthesia or hyposthesia in the C2 or C3 dermatome postoperatively. There has been one tumor recurrence in any case till last follow up.

\section{Discussion:}

At cranio-vertebral junction and higher cervical spinal region meningioma are commoner than schwannoma (3:1). Here other rare tumors are dermoids, teratoma, paraganglioma, intradural extraosseous chordomas ${ }^{(4)}$. Spinal schwannomas make up approximately $30 \%$ of all primary spinal cord tumors. $70 \%$ schwannoma arises from sensory root, $20 \%$ from motor roots and rest 
from both motor and sensory roots ${ }^{5,6}$. About $75 \%$ schwannomas are intradural, $10 \%$ intra-extradural and rest $(15 \%)$ are extradural ${ }^{(7)}$. Though some authors have noted a predominance of extradural location of schwannomas at $\mathrm{C}-2^{2-4,8-12}$. Among the schwannomas arising from C1, C2, \& C3 spinal roots, C2 spinal root tumors are commoner and constitutes $15 \%$ of all spinal schwannomas ${ }^{(1-3,7,9,10-19)}$. In our series, among the $\mathrm{C} 1, \mathrm{C} 2$ and $\mathrm{C} 3$ spinal schwannoma, $11(71 \%)$ originated from $\mathrm{C} 2$ spinal nerve root. A multiplicity of schwannomas is frequently noted in cases involving NF Type 1. A multiplicity of schwannomas at any spinal level is reported in approximately $4 \%$ of cases $^{8,15}$. Multiple schwannoma was absent on our series. In our series male and female ratio was almost equal, whereas other authors had reported a higher incidence of these tumors in females $(3,6,9)$. Symptoms and signs are usually diagnostic in nature. However, unusual symptoms of syncopal attacks, migraine headaches, and unrelated motor \& sensory symptoms, can lead to misdiagnosis ${ }^{(2,20-}$ 24). In one of our case there was history of syncopal attack and fall. These tumors are slow growing and usually attain a large size before becoming symptomatic (2). Dumbbellshaped tumors located elsewhere in the spine are gener-ally classified as intraspinal, foraminal, and extraforaminal ${ }^{(11)}$ and can also occur at high cervical region $(8,10,11,25)$. We conveniently divided these tumors into intradural, intraextradural and extradural group. Malignant changes of such tumor are marked by infiltration of paraspinal muscles and destruction which is rare ${ }^{2}$. These tumors are located lateral, anterolateral, or anterior to the spinal cord. Several posterior, posterolateral, lateral, and anterolateral approaches have been described to surgically approach these tumors $(8,10,11,15,26)$. But we are convinced from our small experience that standard midline posterior approach is suitable and most appropriate to resect almost all types of C1, C2 and $\mathrm{C} 3$ schwannomas with transtumoral resection techniques. A similar surgical strategy had been reported by several investigators in the past $10,11,27,28$. These tumors are usually moderately vascular and firm inconsistency. Such schwannomas are relatively simple to resect because they have a well-defined arachnoid plane of dissection intradurally and well defined capsule extradurally ${ }^{2}$. The exposure used in the surgery (midline posterior approach) is standard and quick and there is no need for manipulation of any cranial nerves, blood vessels, or joints to affect exposure ${ }^{2}$. Some authors have suggested proximal control of the VA prior to tumor resection ${ }^{(8,29)}$. There is a low risk of VA injury in this surgery. So preoperative angiography or intraoperative proximal or distal control of the VA does not appear to be necessary $(13,30)$. Concerning bony stability, after laminectomy of cervical spine, instability or deformity frequently occurred, especially in dumbbell type tumor, in which cases additional bony removal is required to remove the tumor. Although no immediate instability is noted, long time follow up is advised for this problem ${ }^{(15)}$. But if instability is present it should be stabilized immediately (2). In our series we did not face any instability. According to the new WHO classification of brain tumors ${ }^{(31)}$, tumors of cranial and spinal nerves are classified as-schwannoma /neurinoma (variants: cellular, plexiform, melanotic), neurofibromas (circumscribed, plexiform), malignant peripheral nerve sheath tumor (MPNST) (neurogenic sarcoma, anaplastic neurofibroma, "malignant schwannoma"). Variants of MPNST are epithelioid, MPNST with divergent mesenchymal and/or epithelial differentiation and melanotic ${ }^{(31)}$. Again histopathologically, spinal schwannoma may be Antoni A and Antoni B type. Type A tissue is highly cellular and demonstrates nuclear palisading and associated Verocay bodies, which may reflect their prominent extracellular matrix and secretion of laminin. Type B tissue is loosely organized with myxomatous and cystic changes and may represent degenerated Antoni A tissue (25). Successful tumor resection results in rapid and sustained neurological recovery $(2,27,28)$. Total tumor resection is advocated by several authors for complete treatment of the disease. The significant chance of early tumor recurrence in a partially excised tumor is known ${ }^{(3)}$, and every attempt should be made to remove them completely ${ }^{(2)}$. In spite of the critical location of these tumors, with an anterior or anterolateral extension to the spinal cord and a relationship with vital neural structures \& the VA, surgery for C1, C2 \& C3 schwannoma is usually very successful. If the anatomy of the tumor in relationship to normal structures in the vicinity is appropriately understood, then surgery in these formidable-looking tumors is relatively uncomplicated ${ }^{8-11}$.

\section{Conclusion:}

Among high cervical spinal schwannomas $\mathrm{C} 2$ nerve root originating tumors are predominant. Proper 3-D anatomical orientation \& physiological knowledge, deep neuro-radiological observation, pathological 
appreciations and micro-neurosurgical skill and expertization can make the surgical management of these tumors (in a surgically complex site), simple with gratifying result without extensive bone removal or soft tissue manipulation through a standard midline posterior approach.

\section{References:}

1. Belzberg AJ, Campbell JN. Neoplasms of the peripheral nerves. In Wilkins RH, Rengachary SS, editors: Neurosurgery. 2nd edition. New York: McGraw-Hill; 1996. pp. 3217-3223.

2. Goel A, Muzumdar D, Nadkarni T, Desai K, Dange N, Chagla A. Retrospective analysis of peripheral nerve sheath tumors of the second cervical nerve root in 60 surgically treated patients. J Neurosurg Spine 2008;8:129-134.

3. Lot G, George B. Cervical neuromas with extradural components: surgical management in a series of 57 patients. Neurosurgery 1997;41:813-822.

4. Guidetti B, Spallone A. Benign extramedullary tumors of the foramen magnum. Adv Tech Stand Neurosurg 1988;16: 83-120.

5. Heros RC. Lateral suboccipital approach for vertebral and vertebrobasilar artery lesions. J Neurosurg 1986;64:559562.

6. Lot G, George B. The extent of drilling in lateral approaches to the cranio-cervical junction area from a series of 125 cases. Acta Neurochir (Wien) 1999;141:111-118.

7. Levy WJ, Latchaw J, Hahn JF, Sawhny B, Bay J, Dohn DF. Spinal neurofibromas: a report of 66 cases and a compari- son with meningiomas. Neurosurgery 1986;18:331-334.

8. George B, Lot G. Neurinomas of the first two cervical nerve roots: a series of 42 cases. J Neurosurg 1995;82:917-923.

9. Krishnan P, Behari S, Banerji D, Mehrotra N, Chhabra DK, Jain VK. Surgical approach to C1-C2 nerve sheath tumors. Neurol India 2004;52:319-324.

10. Kyoshima K, Uehara T, Koyama J, Idomari K, Yomo S. Dumbbell C2 schwannomas involving both sensory and motor rootlets: report of two cases. Neurosurgery 2003; 53:436-440.

11. McCormick PC. Surgical management of dumbbell tumors of the cervical spine. Neurosurgery 1996;38:294-300.

12. Nittner K. Spinal meningiomas, neuromas and neurofibromas, and hourglass tumors. In Vinken PH, Bruyn GW editors. Handbook of Clinical Neurology: Tumours of the Spine and Spinal Column New York: Elsevier; 1976.pp. 177-322.

13. Halliday AL, Sobel RA, Martuza RL. Benign spinal nerve sheath tumors: their occurrence sporadically and in neurofi- bromatosis types 1 and 2. J Neurosurg 1991; 74:248-253.

14. Kim P, Ebersold MJ, Onofrio BM, Quast LM. Surgery of spinal nerve schwannoma. Risk of neurological deficit after resection of involved root. J Neurosurg 1989;71:810-814.
15. Klekamp J, Samii M. Surgery of spinal nerve sheath tumors with special reference to neurofibromatosis. Neurosurgery 1998;42:279-290.

16. Love JG, Dodge HW Jr. Dumbell (hourglass) neurofibromas affecting the spinal cord. Surg Gynecol Obstet 1952;94:161-172.

17. Onofrio BM. Intradural extramedullary spinal cord tumors. Clin Neurosurg 25:540-555, 1978.

18. Selosse P, Granieri U. Spinal intradural meningiomas and neurinomas. Review of the literature and current situation. Neurochirurgie 1968;14:135-154.

19. Seppälä MT, Haltia MJ, Sankila RJ, Jääskeläinen JE, Heiskanen O. Long-term outcome after removal of spinal neurofibroma.J Neurosurg 1995;82:572-577.

20. Conrad B, Mergner T. High cervical neurinoma (C1/C2) diagnosed falsely as multiple sclerosis because of trigeminal neuralgia. Arch Psychiatr Nervenkr 1979;227: 33-37.

21. Fields WS, Zulch KJ, Maslenikov V. High cervical neurinoma. Special neurologic and radiologic featues. Zentralbl Neurochir 1972;33:99-102.

22. Goldhammer L. Second cervical root neurofibroma and ipsilateral migraine headache. Cephalalgia 1993;13:132- 134.

23. Nagasawa $\mathrm{S}$, Ohtsuki $\mathrm{H}$. A case of $\mathrm{C} 2$ neurinoma suffering syncopal episodes. No Shinkei Geka 1991;19:589-593, 1991.

24. Sairyo K, Henmi T, Endo H. Foramen magnum schwannoma with an unusual clinical presentation: case report. Spinal Cord 1997;35:554-556.

25. Donner TR, Voorhies RM, Kline DG. Neural sheath tumors of major nerves. J Neurosurg 1994;81:362-373.

26. Ducatman BS, Scheithaure BW, Piepgras DG, Reiman HM, II-strup DM: Malignant peripheral nerve sheath tumors. A clinicopathologic study of 120 cases. Cancer 1986;57: $2006-2021$.

27. Yasuoka S, Okazaki H, Daube JR, MacCarty CS. Foramen magnum tumors. Analysis of 57 cases of benign extramedullary tumors. J Neurosurg 1978;49:828-838.

28. Takami T, Yamagata T, Chokyu I, Ikeda H, Tsuyuguchi N, Ohata K. Surgery of Spinal Nerve Sheath Tumors Originating From $\mathrm{C} 1$ or $\mathrm{C} 2$ of High Cervical Spine. Neurologia medico-chirurgica 2010;50:1044-1049.

29. Yong Yu, Xiaobiao Zhang, Fan Hu, Tao Xie, Ye Gu. Minimally invasive microsurgical treatment of cervical intraspinal extramedullary tumors. J Clin Neurosci 2011; 18:1168-1173.

30. George B, Laurian C, Keravel Y, Cophignon J. Extradural and hourglass cervical neurinomas: the vertebral artery problem. Neurosurgery 1985;16:591-594.

31. Steinberg GK, Drake CG, Peerless SJ. Deliberate basilar or vertebral artery occlusion in the treatment of intracranial aneurysms. Immediate results and long-term outcome in 201 patients. J Neurosurg 1993;79:161-173.

32. Kleihues P, Burger PC, Scheithauer BW. The new WHO classification of brain tumors. Brain Pathol 1993;3:255268. 